\title{
Methode Aplikasi Bangunan Krib Sebagai Pelindung terhadap Bahaya Erosi Tebing Sungai
}

\author{
Suharjoko \\ Staft Pengajar Program Studi D-III Teknik Sipil FTSP ITS \\ email: suharjoko_hydro@ce.its.ac.id
}

\begin{abstract}
ABSTRAK
Untuk tujuan disain suatu bangunan krib, perlu dilakukan pengkajian dengan menggunakan model, sementara membangun model baik model fisik maupun model matematis memerlukan dana yang cukup besar. Oleh karena itu Suharjoko ( 2001) telah mengkaji dengan melakukan simulasi numerik terhadap 45 kasus yaitu terdiri dari tiga model krib yang di dibedakan oleh sudut antara krib dengan tebing sungai, setiap modelnya terdapat tiga variasi yang dibedakan oleh ukuran panjang krib dan setiap variasi dikaji terhadap lima kasus yang dibedakan oleh kecepatan arusnya. Tujuan penelitian adalah untuk mendapatkan pedoman perencanaan aplikasi bangunan krib yang sesuai.

Dari hasil simulasi diperoleh bahwa parameter penting yang menjadi penentu adalah lebar sungai (B), Kecepatan arus (v), kedalaman air (h), panjang krib (P), arah krib $(\alpha)$ itu dipasang dan panjang perlindungan yang dihasilkan (D). Kemudian antara parameterparameter penting yang berpengaruh dengan cara penyelesaian analisa dimensi dicari hubungannya. Dari penyelesaian tersebut didapat hubungan antara bilangan Froude ( Fr. ) dengan Dh/ PB. Besarnya bilangan Froude (Fr) adalah V/ $\sqrt{g h}$

Hasil temuan pada studi ini menghasilkan suatu grafik hubungan antara bilangan Froude (Fr.) dengan Dh/ PB sehingga memberikan kemudahan dalam perencanaan bangunan Krib, dengan demikian akan sangat menghemat biaya disain karena tahapan studi simulasi tidak lagi perlu dilakukan dalam merencanakan bangunan krib tersebut.
\end{abstract}

\section{PENDAHULUAN}

\section{A. Latar Belakang}

Pada sungai dimana kecepatan arusnya tinggi tentu menimbulkan erosi, baik yang tejadi di tebing maupun di dasar sungai, oleh karena itu diperlukan suatu bangunan perlindungan. Bangunan perlindungan tebing dapat berupa plengsengan (lining), tembok, turap, bronjong, krib dan lain-lain. Bangunan Krib adalah salah satu bangunan perlindungan yang dipasang melintang pada tebing sungai, yang tujuannnya untuk memperlambat kecepatan arus di sekitar bangunan krib tersebut sehingga proses erosi akan terhindari bahkan akan terjadi proses sedimentasi. Dengan demikian pada tebing yang semula terjadi proses erosi menjadi terlindungi bahkan terjadi endapan (sedimentasi) akibat adanya bangunan krib tersebut. Namun untuk kebutuhan perencanaan bangunan krib perlu dilakukan analisa efektifitas tata letak bangunan krib tersebut apakah harus tegak lurus atau menyudut dan berapa panjang krib yang baik, untuk itu perlu dilakukan pengkajian dan analisa terhadap faktor-faktor yang berpengaruh. Untuk melakukan pengkajian tersebut dapat dilakukan dengan suatu model, baik model fisik maupun model matematis sementara membangun model memerlukan dana yang cukup besar. Oleh karena itu Suharjoko, 2001 telah melakukan penelitian dengan membangun model matematik. Model ini merupakan suatu penyelesaian persamaan aliran tak tunak dua Dimensi Horizontal dengan methode karakteristik.

Model matematik tersebut dilakukan untuk mengkaj i terhadap 45 kasus model krib yang terdiri dari tiga model yang di yang dibedakan oleh sudut antara krib tersebut terhadap tebing sungai. Dan setiap modelnya terdapat tiga variasi yang dibedakan oleh ukuran panjang krib dan setiap variasi dikaji terhadap lima kasus yang dibedakan oleh kecepatan arusnya. 
Hasil simulasi diperoleh bahwa parameter penting yang menjadi penentu adalah lebar sungai, kecepatan arus, kedalaman air, panjang krib, arah krib itu dipasang dan panjang perlindungan yang dihasilkan. Dari parameter yang dihasilkan tersebut dicari hubungannya sedemikian hingga diperoleh suatu fungsi atau hubungan antar parameter tersebut menjadi hubungan yang general. Dengan demikian diperoleh suatu methode perncanaan bangunan krib yang mudah dalam aplikasi disainnya dan tidak perlu lagi melalui kajian.

\subsection{Tujuan dan Manfaat}

Tujuannya adalah melakukan kajian sedemikian hingga diperoleh hubungan antara parameter penting yang berpengaruh tersebut terhadap perlindungan yang dihasilkan oleh bangunan krib terhadap tebing sungai sehingga diperoleh suatu fungsi atau hubungan antar parameter menjadi hubungan yang general.

Sedangkan manfatnya adalah diperoleh kemudahan dalam merencanakan bangunan krib tersebut sebagai perlindungan sungai sehingga dapat menghemat energi dan biaya yang semula dalam merencanakan bangunan krib harus melalui kajian dengan model menjadi hitungan yang amat sederhana.

\section{METODOLOGI}

Tahap pertama dilakukan running model terhadap berbagai kasus dan dilanjutkan analisa terhadap setiap hasil running model yang dihasilkan yakni melakukan penilaian terhadap besaran parameter yang dihasilkan.

Tahap kedua melakukan analisa non-dimensi terhadap parameter penentu untuk mendapatkan hubungan antar parameter tersebut.

Tahap ketiga menghitung terhadap nilai parameter yang dihasilkan untuk mendapatkan hubungan antar parameter model dan kasus.

Tahap keempat melakukan analisa untuk mendapatkan hubungan antar parameter tersebut.

\section{TINJ AUAN PUSTAKA}

\subsection{Model Matematik}

Model ini merupakan suatu penyelesaian persamaan aliran tak tunak (unsteady) dua Dimensi Horizontal dengan methode karakteristik. Persamaan aliran tak tunak dua Dimensi Horizontal adalah terdiri dari persamaan momentum dan persamaan kontinuitas dari Navier Stokes berikut ini

Persamaan kontinuitas :

$\frac{\partial \eta}{\partial t}+\frac{\partial(h u)}{\partial x}+\frac{\partial(h v)}{\partial y}=0$

Persamaan momentum :

$\frac{\partial v}{\partial t}+u \frac{\partial v}{\partial x}+v \frac{\partial v}{\partial y}=Y-\frac{1}{\rho} \frac{\partial p}{\partial y}+v \nabla^{2} v$

$\frac{\partial u}{\partial t}+u \frac{\partial u}{\partial x}+v \frac{\partial u}{\partial y}=X-\frac{1}{\rho} \frac{\partial p}{\partial x}+v \nabla^{2} u$

dimana $\cdot \nabla^{2}=\left(\frac{\partial^{2}}{\partial x^{2}}+\frac{\partial^{2}}{\partial y^{2}}\right)$

$$
\begin{aligned}
u \& v= & \text { Kecepatan rerata vertikal arus arah } \\
& \quad \mathrm{x} \cdot \text { dan arah } \mathrm{y}, \\
h \quad & \text { Kedalaman sungai, } \\
\eta \quad & \text { Tinggi air terhadap bidang } \\
& \text { Persamaan atau tinggi pasang } \\
& \text { surut. }
\end{aligned}
$$

Persamaan di atas diturunkan mengikuti konsep gerakan partikel air dari tempat $(x, y, z)$ menuju ke tempat $(x+d x, y+d y, z+d z)$ dalam selang waktu dt. Pada Gambar 1 berikut ditunjukkan perubahan kecepatan partikel/gerak zat cair arah $x, y, z$ dalam selang waktu dt yaitu suatu perubahan gerakan pertikel dalam 3-Dimensi. 


\section{ISSN.1907-753X}

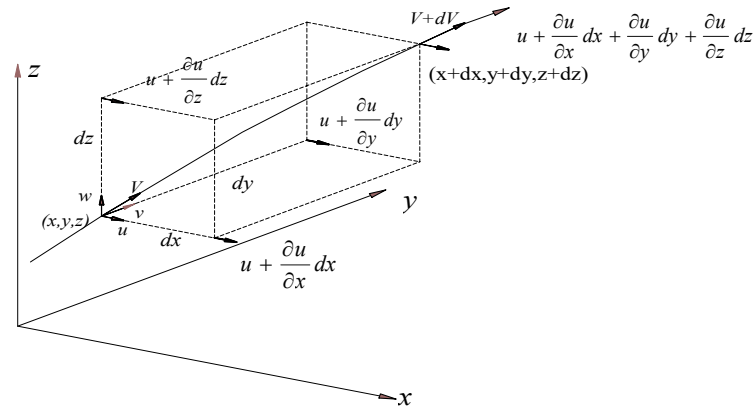

Gambar 1: $\quad$ Perubahan kecepatan partikel zat cair arah $x, y, z$ dalam selang waktu $d t$.

Kemudian dengan mengeliminasi gerakan arah vertical maka persamaan menjadi persamaan gerak aliran 2 Dimensi Horizontal seperti yang ditunjuk pada persamaan 1 dan 2 diatas.

Selanjutnya persamaan defferensial dari persamaan aliran di atas diselesaikan secara numeris dengan methode karakteristik kompotabel Triatmadja (1990) yang merupakan

Hasil akhir dari penyelesaian tersebut diperoleh suatu skema karakteristik sebagai berikut :

$\eta_{h}=\bar{\eta}-\left(u h_{x}+v h_{y}+h u_{x}+h v_{y}\right) \Delta t+$

$\left\{1-2\left(c^{2}+u^{2}+v^{2}\right)(\Delta t / \Delta s)^{2}\right\}(\eta-\bar{\eta})^{2}-$

$\left[\left\{(\Delta s / \Delta t)^{2}-2\left(c^{2}+u^{2}+v^{2}\right)\right\}(u-\bar{u})-4 g u(h-\bar{h}](\Delta t / \Delta s)^{2}\right.$

$\{4 h u(u-\bar{u})+4 h v(v-\bar{v})\}(\Delta t / \Delta s)^{2}$.

$u_{h}=\bar{u}-\left\{u u_{x}+v u_{y}+g \eta_{x}\right\} \Delta t$

$-\frac{g v\left(u^{2}+v^{2}\right)^{0,5}}{C_{2}^{2} \bar{h}} \Delta t-v\left(\frac{\partial^{2} v}{\partial x^{2}}+\frac{\partial^{2} v}{\partial y^{2}}\right) \Delta t+$

$-\frac{g u\left(u^{2}+v^{2}\right)^{0,5}}{C_{z}{ }^{2} \bar{h}} \Delta t-v\left(\frac{\partial^{2} u}{\partial x^{2}}+\frac{\partial^{2} u}{\partial y^{2}}\right) \Delta t$

$v_{h}=\bar{v}-\left\{u v_{x}+v v_{y}+g \eta_{y}\right\} \Delta t-$

$\left\{(\Delta s / \Delta t)^{2}-2\left(c^{2}+u^{2}+v^{2}\right)\right\}(v-\bar{v})-4 g v\left(h-\bar{h} \mid(\Delta t / \Delta s)^{2}\right.$

$-\frac{g v\left(u^{2}+v^{2}\right)^{0,5}}{C_{z}^{2} \bar{h}} \Delta t-v\left(\frac{\partial^{2} v}{\partial x^{2}}+\frac{\partial^{2} v}{\partial y^{2}}\right) \Delta t$,

Sesuai dengan jaring hitungan maka unsurunsur yang tertulis pada persamaan di atas (Persamaan 3.24, 3.25 dan 3.26), dapat didefinisikan sebagai berikut:

$$
\begin{aligned}
& \frac{\partial^{2} u}{\partial x^{2}}=\left(u_{(i+1, j)}-2 u_{(i, j)}+u_{(i-1, j)}\right) / \Delta x^{2}, \\
& \frac{\partial^{2} u}{\partial y^{2}}=\left(u_{(i, j+1)}-2 u_{(i, j)}+u_{(i, j-1)}\right) / \Delta y^{2}, \\
& \frac{\partial^{2} v}{\partial x^{2}}=\left(v_{(i+1, j)}-2 v_{(i, j)}+v_{(i-1, j)}\right) / \Delta x^{2}, \\
& \frac{\partial^{2} v}{\partial y^{2}}=\left(v_{(i, j+1)}-2 v_{(i, j)}+v_{(i, j-1)}\right) / \Delta y^{2}, \\
& h=\eta+h o, \\
& \Delta s=\Delta x=\Delta y,
\end{aligned}
$$

$c=$ Cepat rambat gelombang, $\left(g h_{(i, j)}\right)^{0,5}$,

$C_{z}=$ Koefisien Chezy ,

$v=$ Viskositas kinematis $=1 \times 10^{-3}$.

Persamaan numeric di atas kemudian ditulis dalam bahasa program komputer yang telah diselesaikan oleh Suharjoko (1999), dengan menggunakan bahasa Program Visual Basic.

\subsection{Analisa Kasus dan Model}

Dengan menggunakan program tersebut telah dikaji (1999) terhadap 45 kasus yaitu terdiri dari tiga model krib yang di dibedakan oleh sudut antara krib dengan tebing sungai, setiap modelnya terdapat tiga variasi yang dibedakan oleh ukuran panjang krib dan setiap variasi dikaji terhadap lima kasus yang dibedakan oleh kecepatan arusnya.

Hasil model diatas sebagai dicontohkan pada Gambar 2 adalah gambar vektor kecepatan disekitar Krib miring dengan kecepatan di hulu $=0.6 \mathrm{~m} / \mathrm{dt}$, Gambar 3 adalah gambar vektor kecepatan disekitar Krib miring dengan kecepatan di hulu $=0.4 \mathrm{~m} / \mathrm{dt}$ dan Gambar 4. kontour distribusi kecepatan disekitar krib.

Dari contoh gambar yang dihasilkan tersebut dapat diketahui bahwa di sekitar tebing sungai yang diharapkan dilindungi dari bangungan krib tersebut telah mencapai distribusi kecepatan kurang dari 0,25 m/ dt.

Pengamatan serupa dilakukan pada hasil running model terhadap ke 45 kasus yang yang direncanakan. 


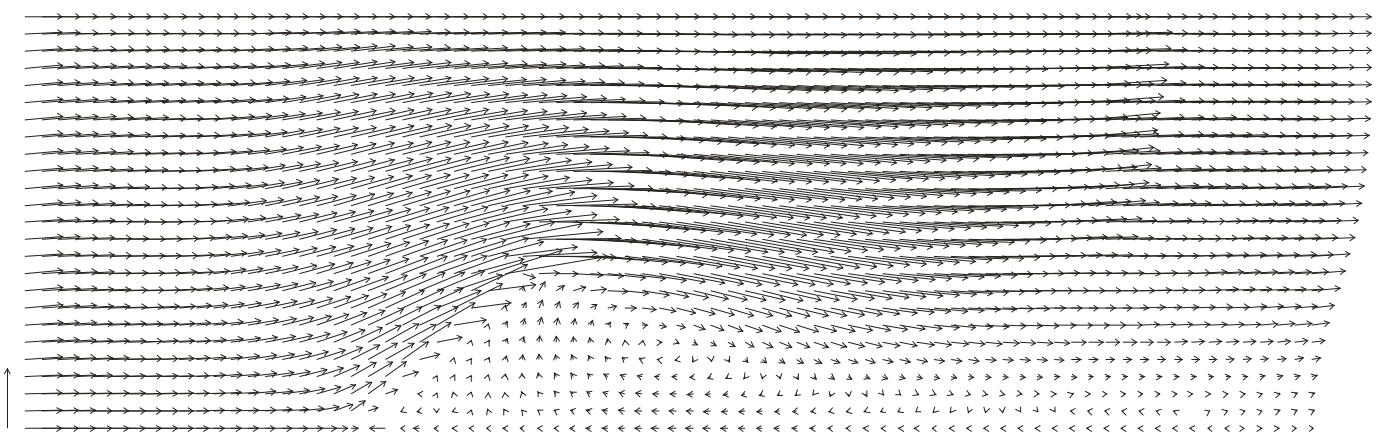

Gambar 2 : Gambar vektor kecepatan disekitar Krib miring dengan kecepatan di hulu $=0.6 \mathrm{~m} / \mathrm{dt}$,

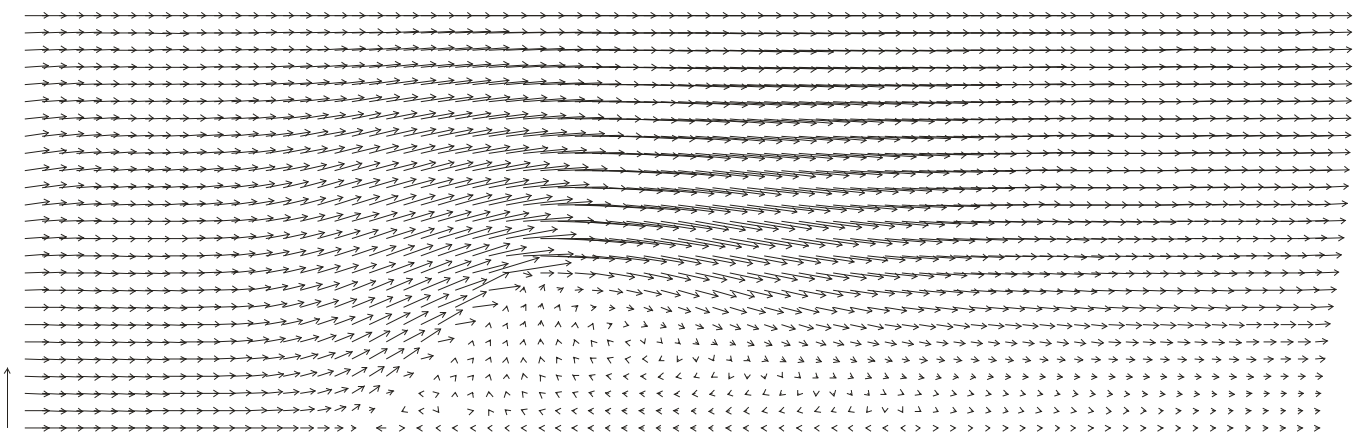

Gambar 3 : Gambar vektor kecepatan disekitar Krib miring dengan kecepatan di hulu =0.4 m/dt,

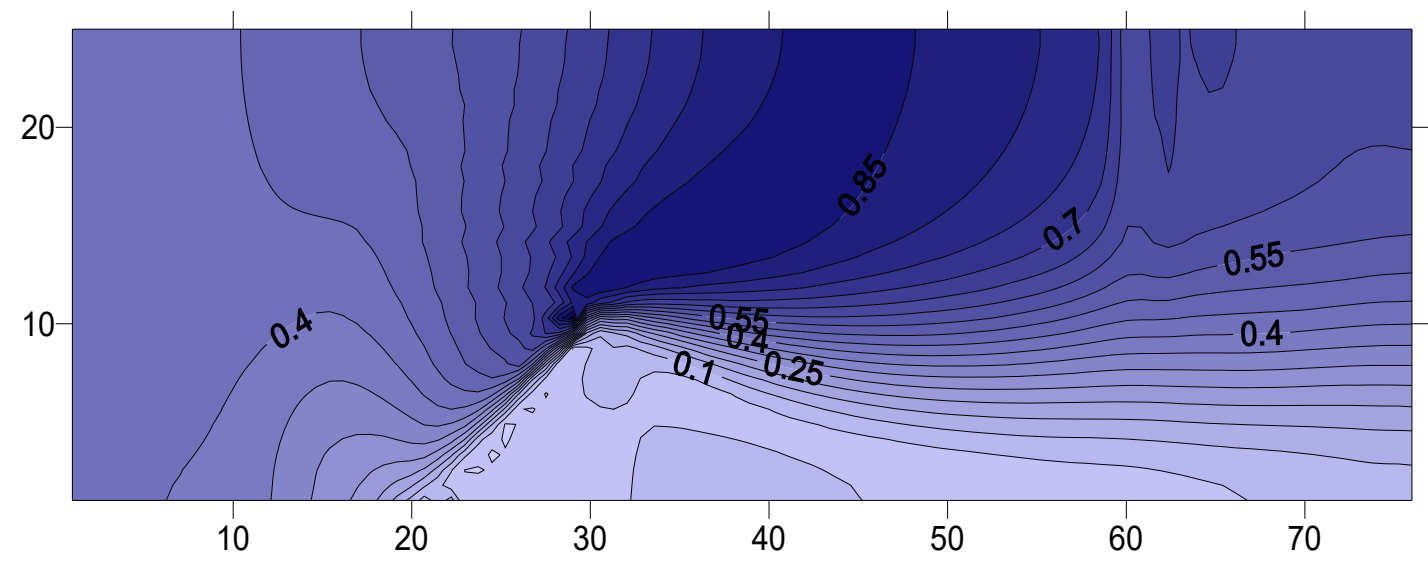

Gambar 4 : Kontur distribusi kecepatan disekitar disekitar Krib miring dengan kecepatan di hulu $=0.4 \mathrm{~m} / \mathrm{dt}$

Hasil simulasi numeric terhadap 45 kasus model krib yaitu parameter penting yang menjadi penentu adalah lebar sungai, kecepatan arus, kedalaman air, panjang krib, arah krib itu dipasang dan panjang perlindungan yang dihasilkan dicatat dan kemudian di analisa untuk dicari hubungan pengaruhnya.

\subsection{Hubungan Antara Parameter Penting}

Untuk mendapatkan hubungan antara parameter-parameter yang berpengaruh tetapi dalam bentuk general maka dilakukan analisa tak berdimensi. Pada Tabel 1. berikut ini ditunjukkan penurunan analisa non-dimensi dengan cara step wise. 
Dengan merujuk pada Gambar 5, parameterparameter yang akan dicari hubungannya adalah :

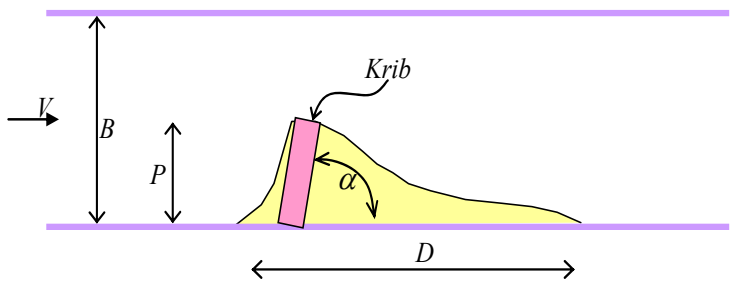

Gambar 5 : Parameter - parameter dimana :

$L \quad$ : Panjang tebing yang terlindungi

ค. : Kerapatan air

u. : kecepatan rata-rata searah dengan alur sungai

v. : kecepatan rata-rata tegak lurus dengan alur sungai

$h$ : kedalaman air

$g \quad$ : percepatan grafitasi

$v$ : viskositas kinematis

$P \quad$ : panjang krib

$B$ : lebar sungai

$A$ : sudut yang dibentuk oleh krib dengan garis tebing sungai

Tabel 1. Tabel penurunan analisa nondimensi dengan cara step wise

\begin{tabular}{|c|c|c|c|c|c|c|c|c|c|}
\hline & $\boldsymbol{D}$ & $\boldsymbol{\rho}$ & $\boldsymbol{u}$ & $\mathbf{h}$ & $\boldsymbol{g}$ & $\boldsymbol{v}$ & $\boldsymbol{p}$ & $\boldsymbol{b}$ & $\operatorname{tg} \boldsymbol{\alpha}$ \\
\hline$\rho\left(\mathrm{M} / \mathrm{L}^{2}\right)$ & $\mathrm{L}$ & $\mathrm{M} / \mathrm{L}^{2}$ & $\mathrm{~L} / \mathrm{T}$ & $\mathrm{L}$ & $\mathrm{L} / \mathrm{T}^{2}$ & $\mathrm{M} / \mathrm{LT}$ & $\mathrm{L}$ & $\mathrm{L}$ & 1 \\
\hline & $D$ & & $u$ & $h$ & $g$ & $v / \rho$ & $p$ & $b$ & 1 \\
\hline$u(\mathrm{~L} / \mathrm{T})$ & $\mathrm{L}$ & & $\mathrm{L} / \mathrm{T}$ & $\mathrm{L}$ & $\mathrm{L} / /^{2}$ & $\mathrm{~L}^{2} / \mathrm{T}$ & $\mathrm{L}$ & $\mathrm{L}$ & 1 \\
\hline & $D$ & & & $h$ & $g / u^{2}$ & $v / \rho u$ & $p$ & $b$ & 1 \\
\hline$h(\mathrm{~L})$ & $\mathrm{L}$ & & & $\mathrm{L}$ & $\mathrm{L}^{-1}$ & $\mathrm{~L}$ & $\mathrm{~L}$ & $\mathrm{~L}$ & 1 \\
\hline & $D / h$ & & & & $g h / u^{2}$ & $v / \rho u h$ & $p / h$ & $b / h$ & 1 \\
\hline
\end{tabular}

Dari penurunan diatas diperoleh bilangan tak berdimensi sebagai berikut :

$\theta \quad\left(D / h, g h / u^{2}, v / \rho u h, p / h, b / h, \operatorname{tg} \alpha\right)$

Dari hasil penurunan tersebut diatas kemudian dengan mengkombinasikan antara bilangan non-dimensi menghasilkan sebagai berikut :

$$
\begin{aligned}
& \frac{D h}{P B} \tan \alpha \approx \frac{\mu}{\rho u h} \frac{u}{\sqrt{g h}} \\
& \frac{D h}{P B} \Leftrightarrow F r
\end{aligned}
$$

Fr adalah Froude Number, $=u / \sqrt{ } g h$,

Dari penyelesaian terebut didapat hubungan antara bilangan Froude ( Fr. ) dengan $\mathrm{Dh} / \mathrm{PB}$, yang dapat ditulis sebagai :

Kemudian dari hasil simulasi terhadap 45 model kasus dicari hubungannya dengan melakukan tabulasi dan menghitung harga bilangan Froude ( Fr. ) dengan Dh/PB seperti yang disajikan pada Tabel 2 berikut ini. Kemudian antara besarnya nilai Froude ( Fr. ) dan Dh/ PB di plot dan kemudian dicari garis regrasinya sebagai yang ditunjuk pada Gambar 6 berikut.

Nampak pada gambar tersebut bahwa dari tiga alternatif model tersebut secara umum dapat dikatakan Model 1 yaitu Krib dengan sudut $\alpha=90^{\circ}$ merupakan pilihan yang paling baik dibanding dengan model lain yang telah diajukan. Oleh karena itu disarankan dipilih bangunan krib tegak lurus dengan arah aliran. 
Tabel 2
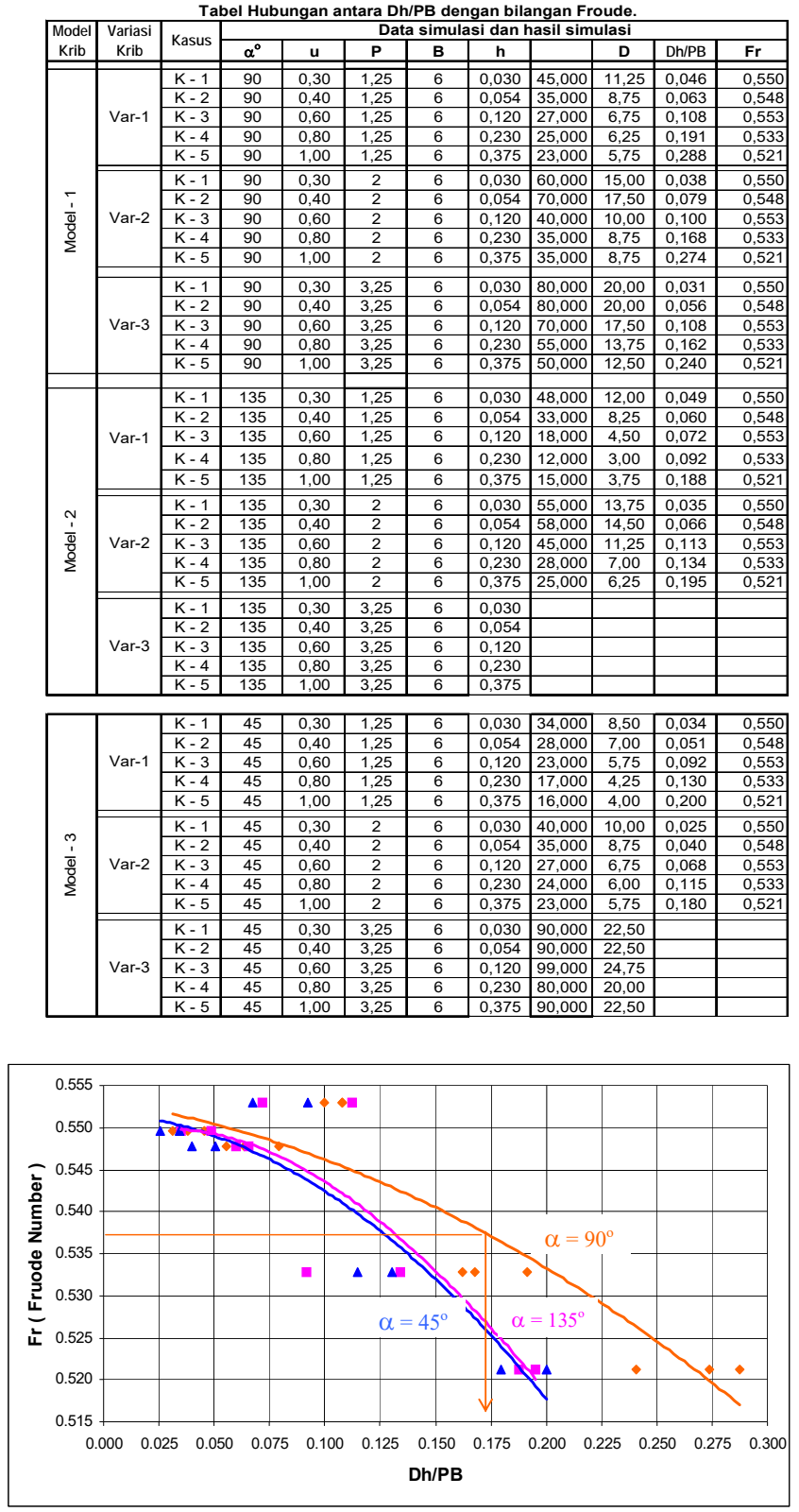

Gambar 6 : Hubungan antara Froude $(F r)$ dengan nilai $D h / P B$ Number

\section{KESIMPULAN}

Hasil temuan pada penelitian diatas yang menghasilkan suatu hubungan antara bilangan Froude ( Fr. ) dengan Dh/ PB, sesuai yang ditunjuk dengan Gambar 6, memberikan kemudahan dalam perencanaan bangunan Krib. Dengan demikian akan sangat menghemat biaya disain karena tahapan studi simulasi tidak lagi perlu dilakukan dalam merencanakan bangunan krib tersebut.

\section{DAFTAR ACUAN}

Suharjoko, 1999, Studi model numeric Aliran "2D Horizontal" pada kasus pemasangan Krib di Estuari, Thesis S2 Program Studi Teknik Sipil Program Pasca Sarjana UGM.

Suharjoko, 2000, Perilaku aliran di sekitar bangunan Krib di Estuari, Majalah IPTEK, ISSN 0953-4098, vol 11, No 2, Mei 2000

Suharjoko, 2001, Model numeric Perilaku Aliran akibat pemasangan Krib di Sungai, Laporan Penelitian - Lemlit ITS.

Suharjoko, 2002, Panjang Perlindungan Pada Tebing Akibat Adanya Bangunan Krib di Sungai , Prosiding Seminar Nasional Sains dan Teknologi - Lemlit ITS, Surabaya 31 juli 2002 